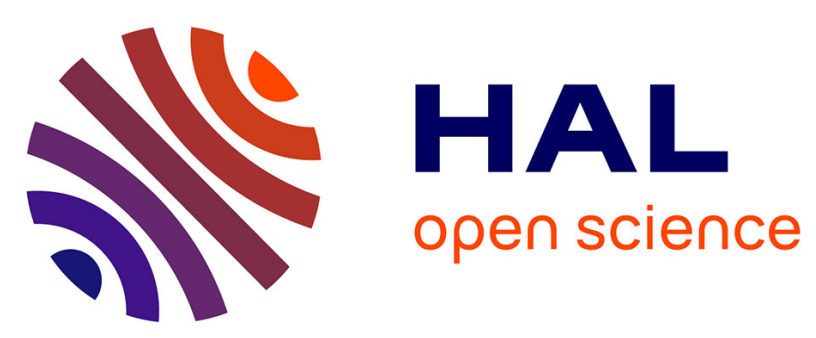

\title{
Oxidative stress and myocardial gene alterations associated with doxorubicin-induced cardiotoxicity in rats persist for two months after treatment cessation
}

Carole Richard, Steliana Ghibu, Stéphanie Delemasure-Chalumeau, Jean-Claude Guilland, Christine Des Rosiers, Marianne Zeller, Yves Cottin, Luc Rochette, Catherine Vergely

\section{To cite this version:}

Carole Richard, Steliana Ghibu, Stéphanie Delemasure-Chalumeau, Jean-Claude Guilland, Christine Des Rosiers, et al.. Oxidative stress and myocardial gene alterations associated with doxorubicininduced cardiotoxicity in rats persist for two months after treatment cessation. Journal of Pharmacology and Experimental Therapeutics, 2011, 339 (3), pp.807-814. 10.1124/jpet.111.185892 . hal03435401

\author{
HAL Id: hal-03435401 \\ https://u-bourgogne.hal.science/hal-03435401
}

Submitted on 18 Nov 2021

HAL is a multi-disciplinary open access archive for the deposit and dissemination of scientific research documents, whether they are published or not. The documents may come from teaching and research institutions in France or abroad, or from public or private research centers.
L'archive ouverte pluridisciplinaire HAL, est destinée au dépôt et à la diffusion de documents scientifiques de niveau recherche, publiés ou non, émanant des établissements d'enseignement et de recherche français ou étrangers, des laboratoires publics ou privés. 
TITLE PAGE

Oxidative stress and myocardial gene alterations associated with doxorubicin-induced cardiotoxicity in rats persist for two months after treatment cessation ${ }^{1}$

Carole Richard, Steliana Ghibu, Stéphanie Delemasure-Chalumeau, Jean-Claude Guilland, Christine Des Rosiers, Marianne Zeller, Yves Cottin, Luc Rochette, Catherine Vergely

Laboratoire de Physiopathologie et Pharmacologie Cardiovasculaires Expérimentales, EA 2979, IFR Santé-STIC, Facultés de Médecine et Pharmacie, 7 bd Jeanne d'Arc, 21000 Dijon, France (C.R., S.D.C., J.C.J, M.Z., Y.C., L.R., C.V.); Department of Pharmacology, Physiology and Physiopathology; Faculty of Pharmacy, University of Medicine and Pharmacy, Cluj-Napoca, Romania (S.G.); Département de nutrition et Institut de Cardiologie de Montréal, Université de Montréal, Québec, Canada (C.D.R.). 


\section{RUNNING TITLE PAGE}

Running title: Genes' alterations in anthracycline cardiotoxicity

Corresponding author: Pr. Catherine VERGELY, Laboratoire de Physiopathologie \& Pharmacologie Cardiovasculaires Expérimentales, EA 2979, IFR Santé-STIC, Facultés de Médecine \& Pharmacie, 7 bd Jeanne d'Arc, 21000 Dijon, France phone: (+33) 3803934 60; fax: (+33) 3803932 93; email: cvergely@bourgogne.fr

\section{Number of text pages: 26}

Number of figures: 4

Number of tables: 4

Number of references: 36

Number of words in the abstract: 247

Number of words in the Introduction: 465

Number of words in the Discussion: 1476

\section{List of non-standard abbreviations:}

ANF: atrial natriuretic factor; AFR: ascorbyl free radical; $\beta$-MHC: myosin heavy chain $\beta$; DHE: dihydroethidium; DOX: doxorubicin; +dP/dT: left ventricular contractility; -dP/dT: left ventricular relaxation; ESR: electron spin resonance; HMOX: heme oxygenase-1; HR: heart rate; LVEDP: left-ventricular end-diastolic pressure; LVDP: left-ventricular developed pressure; LVSP: left-ventricular systolic pressure; qPCR : quantitative polymerase chain reaction; SERCA2a: sarcoplasmic reticulum $\mathrm{Ca}^{+2}$ ATPase; TBARS: thiobarbituric acid reactive substances; VEGFa: vascular growth factor 


\section{Abstract}

The molecular mechanisms underlying doxorubicin (DOX)-induced cardiomyopathy include alterations in cardiomyocytes oxidative stress status as well as in gene expression. While such alterations have been reported during in vivo DOX treatment of animals, it remains to be clarified whether they persist following treatment cessation. To address this question, rats were injected either with saline (1 mL/kg/day/i.p; control: C) or DOX (1 $\mathrm{mg} / \mathrm{kg} /$ day/i.p.) for 10 days (D0 to D9) and, 70 days later (D70), cardiac functional parameters were evaluated in vivo by left ventricular catheterization. Hearts were also harvested for (i) histological analyses as well as measurements of (ii) oxidative stress parameters by various techniques, and (iii) gene expression by qPCR of markers of cardiac pathological remodeling, namely atrial natriuretic factor (ANF), myosin heavy chain $\beta$ ( $\beta$ MHC), vascular growth factor (VEGFa) and sarcoplasmic reticulum $\mathrm{Ca}^{+2}$ ATPase (SERCA2a). Compared with controls, DOX-treated rats displayed marked alterations in most parameters even two months after cessation of treatment. These included (i) lower left ventricular contractility $(+\mathrm{dP} / \mathrm{dt})$, (ii) increased levels of plasma and myocardial oxidative stress markers, namely TBARS or dihydroethidium (DHE) fluorescence; as well as (iii) markedly altered transcript levels for all measured markers of cardiac remodeling, except VEGFa. These changes correlated significantly with $+\mathrm{dP} / \mathrm{dt}$ values assessed in the two groups of animals. In conclusion, this study demonstrated that, as much as two months after cessation of DOX treatment, cardiac alterations persist, reflecting increased oxidative stress as well as pathological remodeling, the latter being linked to the development of contractile dysfunction. 


\section{INTRODUCTION}

Doxorubicin is an anthracycline anti-neoplasic drug used in the treatment of a wide range of solid tumors and of leukemia in children and adults. Despite its good therapeutic results, the clinical use of doxorubicin during chemotherapy is limited by the development of acute, sub-acute, early chronic or late chronic cardiotoxicity (Kremer et al., 2001). Cardiac alterations become more obvious several years after the end of the treatment and may occur as dilated cardiomyopathy leading to congestive heart failure (Giantris et al., 1998; Scully and Lipshultz, 2007).

The different lines of evidence have provided putative mechanisms, but the molecular mechanisms involved in chronic anthracycline cardiotoxicity remain a major topic of discussion. The antitumor activity of DOX is probably distinct from the mechanisms of its cardiotoxicity. Several aspects of this phenomenon, such as apoptosis, alteration of iron and calcium homeostasis have been described, but the exact mechanism is not yet been fully understood. Oxidative stress is believed to be an important pathway in the cardiac side-effects of anthracycline therapy (Tokarska-Schlattner et al., 2006). It is widely known that superoxide anion free radical $\left(\mathrm{O}_{2}{ }^{-}\right)$is generated during the "redox cycling" of anthracycline or after oxido-reduction processes taking place inside the anthracycline-iron complex. Then, $\mathrm{O}_{2}{ }^{\bullet-}$ is transformed into hydroxyl radical $\left(\mathrm{HO}^{\circ}\right)$ in the presence of transition metals or forms peroxinitrite $\left(\mathrm{ONOO}^{-}\right)$in the presence of nitric oxide $\left({ }^{\circ} \mathrm{NO}\right)$. These oxidants induce cellular injury (Delemasure et al., 2007; Simunek et al., 2009). The molecular mechanisms involved in DOX-induced cardiomyopathy have not yet been fully identified but it is likely that they are associated with alterations in the structure and gene expression of cardiac myocytes. In this way, it has been reported that DOX induced effects on L-type calcium channels (Campbell et al., 1996), sarcoplasmic reticulum ATPase (SERCA) (Arai et al., 2000), ryanodine receptors (Wang and Korth, 1995) and $\mathrm{Na}^{+} / \mathrm{Ca}^{+}$exchanger activity (Goldhaber, 
1996). On the other hand, it has also been reported that some pathological cardiac dysfunctions such as hypertrophy were associated with the up-regulation of fetal genes such atrial natriuretic factor (ANF) and isoforms of myosin heavy chain (MHC) (Ritter and Neyses, 2003; Van den Bosch et al., 2006). Early alterations in heart gene expression profiles associated with cardiotoxicity have been studied in vitro and in vivo (Thompson et al., 2010). Using microarrays, Berthiaume and Wallace (Berthiaume and Wallace, 2007) studied global gene expression changes occurring in rats' hearts 5 weeks after sub-chronic DOX treatment. The major findings of this study were a decrease in the expression of genes governing fatty acid metabolism. But to our knowledge, there have been no specific studies on oxidative stress and gene expression a long time after the end of in vivo treatment with DOX in an animal model.

In this context, the aims of our work were to clarify the role of oxidative stress and the expression of certain genes coding for proteins likely to be implicated in DOX-induced cardiac injury two months after cessation of treatment, and to determine the functional and cellular parameters in the plasma and the myocardium. 


\section{METHODS}

\section{Animals and experimental protocol}

The local ethics committee approved the experimental protocol and the investigators complied with authorization 6007 from the French government, which agrees with the Guide of Care and use of Laboratory Animals published by US National Institutes for Health.

For the purpose of our study, male Wistar rats (Charles-River, L'Abresle, France; 300$350 \mathrm{~g}$ at the beginning of the experiment) were divided into 2 groups.

In the control group $(\mathrm{C}, \mathrm{n}=8)$, rats received saline solution: $1 \mathrm{~mL} / \mathrm{kg} / \mathrm{day}$ intraperitoneally (i.p.) for 10 days; from day 0 (D-0) to day 9 (D9).

In the doxorubicin-treated group (DOX, $\mathrm{n}=8$ ), rats were injected i.p. with $1 \mathrm{mg} / \mathrm{kg} / \mathrm{day}$ DOX (Adriamycin®, Pfizer, Paris, France) for 10 days, from day 0 (D0) to D9. A total dose of $10 \mathrm{mg} / \mathrm{kg}$ doxorubicin was administered over the 10-day period.

The body weight of the rats was measured daily during the period of treatment (D0 to D9), then every 10 days. Moreover, food and water consumption was recorded. Plasma concentrations of lipid peroxides were measured.

At the end of the study, 60 days after the end of the treatment (D70) heart functional parameters were evaluated in vivo by left ventricular catheterization.

\section{Heart functional parameters measured in vivo}

The rats were anaesthetized with sodium thiopental $(60 \mathrm{mg} / \mathrm{kg}$, i.p.) and heparinized (500 IU/kg). Once the thorax had been shaved, a catheter connected to a pressure transducer, was inserted into the left ventricle through chest wall in order to measure the heart rate (HR) and left-ventricular pressures (left-ventricular end-diastolic pressure: LVEDP, left-ventricular systolic pressure: LVSP and left-ventricular developed pressure: LVDP = LVSP-LVEDP) 
during the first minute of cardiac catheterization. Left-ventricle contractility was expressed as $+\mathrm{dP} / \mathrm{dt}$ and left-ventricle relaxation as $-\mathrm{dP} / \mathrm{dt}$.

At the end of the study, blood was taken by cardiac puncture, centrifuged and the plasma was immediately frozen in liquid nitrogen. The hearts were excised, cut into segments and frozen.

\section{Histology}

Collagen detection. The hearts of 3 controls and of 3 DOXO-treated rats were harvested for histological analyses. The heart samples were snap-frozen in isopentane then in OCT compound. Five- $\mu$ m-thick sections were cut using a microtome (CM3050S, Leica microsystems, Germany) and were stained using the Sirius Red protocol (0.1\% Direct Red 80 in saturated picric acid solution), which is specific to fibrillar collagens (collagen I and III). Randomly selected fields were evaluated under a polarized-light microscope (Eclipse 600, Nikon, Champigny-Sur-Marne, France) connected to a digital video camera (Tri CCD, Sony, France). The quantity of collagen was measured using Visilog software (Noesis, France) and expressed as the ratio of the mean area of collagen to the total area.

Superoxide Production. In the presence of superoxide, ethidine, a fluorescent compound, is formed from dihydroethidium (DHE) and thus allows quantification of superoxide production. Frozen heart tissues were fixed for $10 \mathrm{~min}$ in acetone. Slides were incubated in a light-protected humidified chamber at room temperature with DHE $(5 \mu \mathrm{M})$ for 5 min. The slides were immediately analyzed with a computer-based digitizing image system (Microvision, France) using a fluorescent microscope (Eclipse 600, Nikon, France) connected to a video camera (TriCCD, Sony, France). Fluorescence was detected at $590 \mathrm{~nm}$ and carried forward to the nuclear number. Results were expressed in fluorescence intensity/nuclear number. 


\section{Blood/plasma determinations}

Determination of Thiobarbituric Acid Reactive Substances (TBARS). Plasma lipid peroxides were measured using a colorimetric reaction with thiobarbituric acid. $1.5 \mathrm{~mL}$ of trichloroacetic acid/thiobarbituric acid/hydrochloric acid solution was added to $500 \mu \mathrm{L}$ of plasma. The color of the thiobarbituric acid pigment was developed in a water bath at $100^{\circ} \mathrm{C}$ for $15 \mathrm{~min}$. After cooling with ice to room temperature, $1 \mathrm{~mL}$ of $70 \%$ trichloroacetic acid was


at $553 \mathrm{~nm}$. The absorbance values were compared with a standard curve. Results were expressed in $\mu$ moles/g proteins; plasma protein was determined according to the Bradford method (Ghibu et al., 2009). Plasma TBARS were assessed only at the end of the study.

Plasma ascorbyl free radical (AFR) determinations by electron spin resonance (ESR) spectroscopy. Thirty-five $\mu \mathrm{L}$ of plasma samples were inserted into a quartz capillary tube, which was placed in an HS cavity in order to analyze them at room temperature with a Bruker EMX-100 X-band spectrometer (Wissembourg, France). The following parameters were selected for optimal detection of AFR (Vergely et al., 1998): modulation frequency: $100 \mathrm{kHz}$, amplitude modulation: $0.8 \mathrm{G}$, microwave power: $40 \mathrm{~mW}$, microwave frequency: $8.5 \mathrm{GHz}$, conversion time: $40 \mathrm{~ms}$, time constant: $327 \mathrm{~ms}$, scan time: $41 \mathrm{~s}$, gain: $5.10^{5}$, number of scans: 6. The height of AFR signal intensity was measured and expressed in arbitrary units (AU).

\section{Tissue determinations}

Determination of cardiac Thiobarbituric Acid Reactive Substances (TBARSs) Heart lipid peroxides were measured using a colorimetric reaction with thiobarbituric acid. The hearts were homogenized in ice-cold phosphate buffered saline (0.05 M, pH 7). Then, $1.5 \mathrm{~mL}$ 
of trichloroacetic acid/thiobarbituric acid/hydrochloric acid solution was added (see previously). Results were expressed in $\mu \mathrm{M} / \mathrm{g}$ cardiac tissue.

mRNA levels assessed by quantitative polymerase chain reaction (qPCR). Freezeclamped hearts were used to assess mRNA levels for selected marker genes (listed in Table 1) that reflect cardiac remodeling, namely atrial natriuretic factor (ANF), myosin heavy chain $\beta$ ( $\beta$-MHC), vascular endothelial growth factor (VEGFa) and sarcoplasmic reticulum $\mathrm{Ca}^{+2}$ ATPase (SERCA2a), as well as a marker of oxidative stress-induced adaptive response, namely the TF Nrf2 gene, heme oxygenase-1 (HMOX). Gene-specific primer pairs were designed (Beacon Designer 5.0 program) on the basis of rat sequences available in GenBank. Total RNA was extracted with Qiagen RNeasy Plus columns, quantified by an Agilent BioAnalyzer 2100, and assessed by reverse transcription, followed by real-time qPCR, as described previously (Lauzier et al., 2011). Cycling was achieved in a MX3005p cycler (Stratagene, Mississauga, Ontario, Canada); conditions: $95^{\circ} \mathrm{C}$ for $10 \mathrm{~min}$ and 46 cycles at $94^{\circ} \mathrm{C}$ for $15 \mathrm{~s}, 60^{\circ} \mathrm{C}$ for $30 \mathrm{~s}$ and $72^{\circ} \mathrm{C}$ for $30 \mathrm{~s}$.

\section{Statistical analysis}

All data are expressed as means \pm S.E.M. To compare the groups at 2 months after the end of treatment, statistical analyses were performed with the one-factor analysis of variance (ANOVA) test (SigmaStat); ANOVA was followed, if necessary, by a Newman-Keuls test. To compare the evolution of parameters throughout the period of study (period of treatment and period of observation) we used a two-factor repeated measures analysis of variance (ANOVA) test (SigmaStat). Significance was established at a value of $P<0.05$. 


\section{RESULTS}

\section{Body and heart weights, heart weight to body weight ratio}

In the rats, DOX induced a significant loss of body weight starting from the $3^{\text {rd }}$ day of treatment. After interruption of treatment, there was a trend towards recovery of body weight with kinetics identical to those of control rats.

Two months (D70) after the end of the treatment, the hearts of DOX-treated rats weighed significantly less than control hearts. The heart to body weight ratio, which estimates cardiac hypertrophy, was significantly $(\mathrm{P}<0.05)$ increased in the DOX group (Table 2).

\section{Cardiac parameters evaluated in vivo by left ventricle catheterization}

Heart rate (HR) was not affected by DOX treatment at D70 (Table 3). However, left ventricular developed pressure (LVDP), $+\mathrm{dP} / \mathrm{dT}$ and $-\mathrm{dP} / \mathrm{dT}$ were modified 2 months after the end of treatment, animals treated with DOX had significantly lower $+\mathrm{dP} / \mathrm{dT},-\mathrm{dP} / \mathrm{dT}$ and LVDP than controls. These deleterious effects were observed in the left ventricle. The effects in the right ventricle were not significant (data not shown).

\section{Histology}

Collagen detection. Sirius Red staining of heart sections showed apparent collagen type I and III deposition in the left ventricle (Figures 1 and 2). The most consistently and severely affected areas occurred around the branches of the coronary vessels. The main histological alterations in vessels are shown in Figure 1A. DOX increased quantities of collagen in the arterial adventitia: DOX $(293 \pm 98 \%)$ as compared to Controls $(124 \pm 55 \%)$ group $(\mathrm{p}<0.05)$ (Figure 2A). However, no difference was found between the DOX and control group for collagen content in the subepicardial regions of the left-ventricular myocardium (Figure 1B 
and $2 \mathrm{~B}$ ). In contrast, there were focal morphological changes that could be related to the formation of edema.

Heart tissue superoxide anion production. Two months after the end of the treatment, the production of $\mathrm{O}_{2}{ }^{--}$in heart tissue was significantly $(\mathrm{p}<0.05)$ higher in the group of rats treated with DOX than in the Control group (Table 4).

\section{Blood/plasma parameters}

Plasma concentrations of Thiobarbituric Acid Reactive Substances (TBARS). Two months after the end of the treatment, the plasma level of TBARS was significantly higher in the DOX group than in the Control group (Table 4).

Ascorbate radicals $(A F R)$ and AFR/Ascorbate ratio in plasma. There was a significant decrease in plasma concentrations of ascorbate in the group of rats treated with DOX, associated with a significant increase in the AFR to ascorbate ratio (Table 4).

\section{Tissue parameters}

Heart tissue TBARS. Two months after the end of the treatment, levels of TBARS in the hearts of rats from the DOX group were significant higher $(+50 \%, \mathrm{P}<0.05)$ than those in Control hearts (Table 4).

Cardiac transcript levels for selected gene markers of cardiac remodeling. Compared to control hearts, the hearts from DOX-treated rats displayed markedly altered mRNA levels for markers of cardiac remodeling (Figure 3), namely ANF and $\beta$-MHC (increased; respectively 4.8 and 3.2 fold), and SERCA2a (decreased; -25\%) (p<0.001). There was no difference, however, for VEGFa. Interestingly, there were significant correlations between cardiac gene expressions for ANF, $\beta$-MHC and SERCA2a, and $+\mathrm{dP} / \mathrm{dT}$ for the two groups of animals (Figure 4). 


\section{DISCUSSION}

In rats, the administration of a cumulative dose of $10 \mathrm{mg} / \mathrm{kg}$ DOX induced a decrease in body weight, associated with reduced food consumption. After the end of the treatment, during the two months of the experimental design, body weight and food consumption recovered, but did not reach values of the Control group. In our experiment, the cardiac alterations were more obvious, as revealed by a greater deterioration in heart contractility in the rats treated with DOX. This suggests progressive cardiac dysfunction long after exposure to DOX, as is the case in human patients, who may die months or even years after chemotherapy has been stopped.

Two months after the end of treatment, heart weight in the DOX group was lower than in controls. This phenomenon has been described in other studies (Sacco et al., 2003; Richard et al., 2008; Ghibu et al., 2011) and could be explained by the apoptosis of cardiomyocytes (Bennink et al., 2004; Reeve et al., 2007). Two months after the end of treatment, the heart to body weight ratio, an index of cardiac hypertrophy, was higher in the DOX group and was associated with an increase in the semiquantitative scores from the collagen analysis. These results are in accordance with previous studies (Sanchez-Quintana et al., 1994).

In vivo cardiac functional parameters were impaired 2 months after chronic treatment with DOX: with lower left ventricular contractility $(+\mathrm{dP} / \mathrm{dt})$ in DOX hearts, which induced a significant reduction in LVDP. As already observed in our laboratory (Richard et al., 2008), the impairment of contractility is a very late event and is only at its beginnings two months after a cumulative dose of $10 \mathrm{mg} / \mathrm{kg}$ of DOX.

Plasma and heart lipid peroxidation was assessed as TBARS concentrations at the time the rats were killed. To get a better evaluation of plasma oxidative stress, we determined the plasma concentration of vitamin C by HPLC and the plasma ascorbyl free radical levels by ESR spectroscopy. Two months after the end of the treatment, the plasma concentration of 
ascorbate was significantly lower in rats treated with doxorubicin, and this was associated with a significant increase in the AFR to ascorbate ratio. AFR can be considered as an endogenous indicator of oxidative stress and a terminal paramagnetic product of free-radical transformations in the antioxidant defense system (Vergely et al., 1998). The increase in this ratio could be related to the chronic deleterious effects of DOX long after the end of the treatment. In consequence, this phenomenon could be explained by a decrease in hepatic vitamin $\mathrm{C}$ synthesis and by an excess production of free radical species, as we previously reported (Richard et al., 2008).

The evaluation of cardiac oxidative stress by TBARs or by dihydroethidium (DHE) fluorescence showed significantly higher levels of $\mathrm{O}_{2}{ }^{\bullet-}$ production and peroxidation in the DOX group. In a similar short-term study carried out in our laboratory, we found no evidence of cardiac oxidative stress 8 days after treatment with a cumulative dose of $10 \mathrm{mg} / \mathrm{kg}$ doxorubicin (Richard et al., 2008), confirming that tissue oxidative stress is a late event in doxorubicin cardiotoxicity.

As shown in this study, DOX induces an increase in collagen I and III content in arterial adventitia. Our results provide direct evidence that advential tissue may have been affected by DOX; this tissue being a source of inflammatory mediators. In contrast to wellcharacterized processes of endothelial lesion, changes in the adventitia during DOX treatment have been neglected. Our results are in agreement with an earlier study in rats receiving DOX that reported marked fibrosis associated with morphological changes that could be related to edema and inflammation (Yagmurca et al., 2003). Most studies support the view that an increase in oxidative stress plays a key role in the pathogenesis while others suggest the release of vasoactive mediators and hormones (Takemura and Fujiwara, 2007). It is well documented in clinical studies that the spectrum of cardiotoxicity with anthracycline agents 
includes coronary diseases (Swerdlow et al., 2007). Using the isolated-perfused-heart model, we revealed (Delemasure et al., 2007) prolonged deterioration in coronary flow during treatment anthracyclines.

The molecular mechanisms involved in the deleterious effects of DOX on the heart are complex and remain a matter of controversy (Minotti et al., 2004). Mechanisms that have been suggested include alterations in genes important for the structural integrity and enzymatic function of cardiac and vessel myocytes. These phenomena can lead to inadequate maintenance of contractile function in the heart. In our study, we focused on the possible role of various molecular pathways in relationship with oxidative stress and the development of heart failure. HMOX-1 is one of the three isoforms of heme-oxygenase enzyme that catabolizes the degradation of heme into biliverdin with the production of free iron and carbon monoxide (CO). HMOX-1 is induced by stimuli including agents involved in oxidative stress and serves as protective gene in a wide range of pathological situations (Ryter et al., 2006). In our experimental conditions, we found no modifications of HMOX-1 in the myocardium of animals treated with DOX, even though there was an increase in oxidative stress. The lack of HMOX-1 induction by DOX is surprising, since HMOX-1 is an inducible defense mechanism activated ubiquitously. However, the essential role of HMOX-1 takes place during the acute stress adaptation and, in our experimental conditions, levels were measured long time after the end of DOX-treatment.

VEGFa is a pivotal angiogenic factor in most tumors and also appears to be a mediator of angiogenesis in several other disease conditions (Carmeliet and Jain, 2000). Our data demonstrate that VEGFa is expressed in the heart but that DOX-induced cardiotoxicity was not associated with any change in VEGFa expression. Our results are in accordance with data obtained on the mesenteric area showing that DOX did not significantly affect angiogenesis, 
in doses ranging from 1.8 to $10.8 \mathrm{mg} / \mathrm{kg} / \mathrm{w}$, even when co-treated with the antioxidant, $\mathrm{N}$ acetylcysteine (Albertsson et al., 2006). It is clear from our present data that the severe cardiac disorders induced by DOX did not result in a modified VEGFa profile.

Pathological cardiac dysfunction has been associated with the up-regulation of fetal genes such as ANF and $\beta$-MHC (Izumo et al., 1988; Van den Bosch et al., 2006). The important results of our study on DOX-induced cardiotoxicity concern the modifications of mRNA in the genes ANF, $\beta$-MHC and SERCA2a in hearts collected two months after the end of the treatment. We observed a very significant increase in ANF and $\beta$-MHC expression associated with a significant decrease in SERCA2a. A positive and significant correlation was found between SERCA2a expression and $+\mathrm{dP} / \mathrm{dt}$, while there was a significant negative correlation between ANF expression and $+\mathrm{dP} / \mathrm{dt}$ in the hearts of the both groups of animals.

The expression of $\alpha$ and $\beta$ isoforms of MHC genes is developmentally regulated in the myocardium (Lompre et al., 1991). There is growing evidence that the increased expression of $\beta$-MHC in the failing ventricle may serve as a compensatory mechanism to increase contractile efficiency by decreasing the tension cost of contraction (Sanbe et al., 2005). It has been reported (de Beer et al., 2000) that chronic DOX treatment significantly increased the ratio of $\beta$-MHC to $\alpha-\mathrm{MHC}$ in ventricular tissue. Therefore a relationship exists between the decreased contractile performance and the relative increase in $\beta$-MHC expression.

Concerning the molecular impact of treatment with DOX on ANF and SERCA2a expression, these effects are related to the progression of cardiac dysfunction. It has been clearly demonstrated that mRNA levels of the sarcoplasmic reticulum calcium pump were lower in failing than in non-failing hearts (Hasenfuss, 1998). A large body of evidence points to the central role of SERCA2a in the modulation of cardiac relaxation. The levels of these calcium-handling proteins are altered in cardiomyopathies (Kranias and Bers, 2007). Our results are in accordance with the concept that DOX-induced cardiotoxicity depends on the 
down-regulation of the SERCA pump; SERCA was previously shown to be down-regulated by DOX and by oxidative stress induced by hydrogen peroxide (Arai et al., 2000).

Plasma levels of natriuretic peptides increase in patients with severe coronary heart failure and also in patients with asymptomatic left ventricle dysfunction (Ogawa et al., 2002). ANF and B-type natriuretic peptide are also useful markers of ventricular dysfunction in patients undergoing anthracycline therapy (Okumura et al., 2000). To further investigate the markers of DOX-induced cardiac toxicity in our chronic model, we evaluated the RNA expression levels for the fetal gene, ANF, in the myocardium. We observed a substantial increase in ANF mRNA, and a negative correlation with the $+\mathrm{dP} / \mathrm{dt}$ in control animals as well as in DOX-treated animals. Our results are in accordance with the few studies on the subject. Experimental heart failure has been associated with increased ANF mRNA in the left ventricle (Goetze et al., 2006). Because of the strong association between cardiomyocytes hypertrophy and the induction of fetal genes, the expression of ANF and $\beta$-MHC has often been used as a marker of hypertrophy and heart failure, but it remains unclear why and how the frequent transition from hypertrophy to failure occurs.

In conclusion, this study confirmed that, two months after completion of the DOX treatment, the state of animals had deteriorated and that this was associated with a rise in oxidative stress and a modification in the expression of genes coding for proteins related to the development of cardiac dysfunction. 
JPET \# 185892

\section{Acknowledgements}

This work was supported by grants from the Conseil Régional de Bourgogne, the Association de Cardiologie de Bourgogne and the Ligue Contre le Cancer. 


\section{Authorship Contributions}

Participated in Research design: Vergely, Richard, Cottin, Des Rosiers, Rochette, Zeller.

Conducted experiments: Richard, Delemasure-Chalumeau, Ghibu, Des Rosiers.

Contributed new reagents or analytic tools: Guilland, Zeller.

Performed data analysis: Vergely, Richard, Delemasure-Chalumeau, Rochette.

Wrote or contributed to the writing of the manuscript: Vergely, Richard, Des Rosiers, Rochette. 


\section{References}

Albertsson P, Lennernas B and Norrby K (2006) On metronomic chemotherapy: modulation of angiogenesis mediated by VEGE-A. Acta Oncol 45:144-155.

Arai M, Yoguchi A, Takizawa T, Yokoyama T, Kanda T, Kurabayashi M and Nagai R (2000) Mechanism of doxorubicin-induced inhibition of sarcoplasmic reticulum $\mathrm{Ca}(2+)$-ATPase gene transcription. Circ Res 86:8-14.

Bennink RJ, van den Hoff MJ, van Hemert FJ, de Bruin KM, Spijkerboer AL, Vanderheyden JL, Steinmetz N and van Eck-Smit BL (2004) Annexin V imaging of acute doxorubicin cardiotoxicity (apoptosis) in rats. J Nucl Med 45:842-848.

Berthiaume JM and Wallace KB (2007) Persistent alterations to the gene expression profile of the heart subsequent to chronic Doxorubicin treatment. Cardiovasc Toxicol 7:178-191.

Campbell DL, Stamler JS and Strauss HC (1996) Redox modulation of L-type calcium channels in ferret ventricular myocytes. Dual mechanism regulation by nitric oxide and Snitrosothiols. J Gen Physiol 108:277-293.

Carmeliet P and Jain RK (2000) Angiogenesis in cancer and other diseases. Nature 407:249257.

de Beer EL, Bottone AE, van Der Velden J and Voest EE (2000) Doxorubicin impairs crossbridge turnover kinetics in skinned cardiac trabeculae after acute and chronic treatment. Mol Pharmacol 57:1152-1157.

Delemasure S, Sicard P, Lauzier B, Moreau D, Vergely C and Rochette L (2007) Acute administration of epirubicin induces myocardial depression in isolated rat heart and production of radical species evaluated by electron spin resonance spectroscopy. J Cardiovasc Pharmacol 50:647-653. 
Ghibu S, Delemasure S, Richard C, Guilland JC, Martin L, Gambert S, Rochette L and Vergely C (2011) General oxidative stress during doxorubicin-induced cardiotoxicity in rats: Absence of cardioprotection and low antioxidant efficiency of alpha-lipoic acid. Biochimie.

Ghibu S, Lauzier B, Delemasure S, Amoureux S, Sicard P, Vergely C, Muresan A, Mogosan C and Rochette L (2009) Antioxidant properties of alpha-lipoic acid: effects on red blood membrane permeability and adaptation of isolated rat heart to reversible ischemia. Mol Cell Biochem 320:141-148.

Giantris A, Abdurrahman L, Hinkle A, Asselin B and Lipshultz SE (1998) Anthracyclineinduced cardiotoxicity in children and young adults. Crit Rev Oncol Hematol 27:53-68.

Goetze JP, Friis-Hansen L, Rehfeld JF, Nilsson B and Svendsen JH (2006) Atrial secretion of B-type natriuretic peptide. Eur Heart J 27:1648-1650.

Goldhaber JI (1996) Free radicals enhance $\mathrm{Na}+/ \mathrm{Ca} 2+$ exchange in ventricular myocytes. Am J Physiol 271:H823-833.

Hasenfuss G (1998) Alterations of calcium-regulatory proteins in heart failure. Cardiovasc Res 37:279-289.

Izumo S, Nadal-Ginard B and Mahdavi V (1988) Protooncogene induction and reprogramming of cardiac gene expression produced by pressure overload. Proc Natl Acad Sci U S A 85:339-343.

Kranias EG and Bers DM (2007) Calcium and cardiomyopathies. Subcell Biochem 45:523537.

Kremer LC, van Dalen EC, Offringa M, Ottenkamp J and Voute PA (2001) Anthracyclineinduced clinical heart failure in a cohort of 607 children: long-term follow-up study. $J$ Clin Oncol 19:191-196.

Lauzier B, Merlen C, Vaillant F, McDuff J, Bouchard B, Beguin PC, Dolinsky VW, Foisy S, Villeneuve LR, Labarthe F, Dyck JR, Allen BG, Charron G and Des Rosiers C (2011) Post- 
translational modifications, a key process in CD36 function: Lessons from the spontaneously hypertensive rat heart. J Mol Cell Cardiol 51:99-108.

Lompre AM, Mercadier JJ and Schwartz K (1991) Changes in gene expression during cardiac growth. Int Rev Cytol 124:137-186.

Minotti G, Menna P, Salvatorelli E, Cairo G and Gianni L (2004) Anthracyclines: molecular advances and pharmacologic developments in antitumor activity and cardiotoxicity. Pharmacol Rev 56:185-229.

Ogawa K, Oida A, Sugimura H, Kaneko N, Nogi N, Hasumi M, Numao T, Nagao I and Mori S (2002) Clinical significance of blood brain natriuretic peptide level measurement in the detection of heart disease in untreated outpatients: comparison of electrocardiography, chest radiography and echocardiography. Circ J 66:122-126.

Okumura H, Iuchi K, Yoshida T, Nakamura S, Takeshima M, Takamatsu H, Ikeno A, Usuda K, Ishikawa T, Ohtake S and Matsuda T (2000) Brain natriuretic peptide is a predictor of anthracycline-induced cardiotoxicity. Acta Haematol 104:158-163.

Reeve JL, Szegezdi E, Logue SE, Chonghaile TN, O'Brien T, Ritter T and Samali A (2007) Distinct mechanisms of cardiomyocyte apoptosis induced by doxorubicin and hypoxia converge on mitochondria and are inhibited by Bcl-xL. J Cell Mol Med 11:509-520.

Richard C, Lauzier B, Delemasure S, Talbot S, Ghibu S, Collin B, Senecal J, Menetrier F, Vergely C, Couture R and Rochette L (2008) Effects of angiotensin-1 converting enzyme inhibition on oxidative stress and bradykinin receptor expression during doxorubicin-induced cardiomyopathy in rats. J Cardiovas Pharmacol 52:278-285.

Ritter O and Neyses L (2003) The molecular basis of myocardial hypertrophy and heart failure. Trends Mol Med 9:313-321.

Ryter SW, Alam J and Choi AM (2006) Heme oxygenase-1/carbon monoxide: from basic science to therapeutic applications. Physiol Rev 86:583-650. 
Sacco G, Giampietro R, Salvatorelli E, Menna P, Bertani N, Graiani G, Animati F, Goso C, Maggi CA, Manzini S and Minotti G (2003) Chronic cardiotoxicity of anticancer anthracyclines in the rat: role of secondary metabolites and reduced toxicity by a novel anthracycline with impaired metabolite formation and reactivity. $\mathrm{Br} J$ Pharmacol 139:641651.

Sanbe A, James J, Tuzcu V, Nas S, Martin L, Gulick J, Osinska H, Sakthivel S, Klevitsky R, Ginsburg KS, Bers DM, Zinman B, Lakatta EG and Robbins J (2005) Transgenic rabbit model for human troponin I-based hypertrophic cardiomyopathy. Circulation 111:2330-2338. Sanchez-Quintana D, Climent V, Garcia-Martinez V, Macias D and Hurle JM (1994) Extracellular matrix arrangement in the papillary muscles of the adult rat heart. Alterations after doxorubicin administration and experimental hypertension. Basic Res Cardiol 89:279292.

Scully RE and Lipshultz SE (2007) Anthracycline cardiotoxicity in long-term survivors of childhood cancer. Cardiovasc Toxicol 7:122-128.

Simunek T, Sterba M, Popelova O, Adamcova M, Hrdina R and Gersl V (2009) Anthracycline-induced cardiotoxicity: overview of studies examining the roles of oxidative stress and free cellular iron. Pharmacol Rep 61:154-171.

Swerdlow AJ, Higgins CD, Smith P, Cunningham D, Hancock BW, Horwich A, Hoskin PJ, Lister A, Radford JA, Rohatiner AZ and Linch DC (2007) Myocardial infarction mortality risk after treatment for Hodgkin disease: a collaborative British cohort study. J Natl Cancer Inst 99:206-214.

Takemura G and Fujiwara H (2007) Doxorubicin-induced cardiomyopathy from the cardiotoxic mechanisms to management. Prog Cardiovasc Dis 49:330-352. 
Thompson KL, Rosenzweig BA, Zhang J, Knapton AD, Honchel R, Lipshultz SE, Retief J, Sistare FD and Herman EH (2010) Early alterations in heart gene expression profiles associated with doxorubicin cardiotoxicity in rats. Cancer Chemother Pharmacol 66:303-314. Tokarska-Schlattner M, Zaugg M, Zuppinger C, Wallimann T and Schlattner U (2006) New insights into doxorubicin-induced cardiotoxicity: the critical role of cellular energetics. $J \mathrm{Mol}$ Cell Cardiol 41:389-405.

Van den Bosch BJ, Lindsey PJ, Van den Burg CM, Van der Vlies SA, Lips DJ, Van der Vusse GJ, Ayoubi TA, Doevendans PA and Smeets HJ (2006) Early and transient gene expression changes in pressure overload-induced cardiac hypertrophy in mice. Genomics 88:480-488.

Vergely C, Maupoil V, Benderitter M and Rochette L (1998) Influence of the severity of myocardial ischemia on the intensity of ascorbyl free radical release and on post-ischemic recovery during reperfusion. Free Radic Biol Med 24:470-479.

Wang YX and Korth M (1995) Effects of doxorubicin on excitation-contraction coupling in guinea pig ventricular myocardium. Circ Res 76:645-653.

Yagmurca M, Fadillioglu E, Erdogan H, Ucar M, Sogut S and Irmak MK (2003) Erdosteine prevents doxorubicin-induced cardiotoxicity in rats. Pharmacol Res 48:377-382. 


\section{Footnotes}

1 This work was supported by grants from the Conseil Régional de Bourgogne, the Association de Cardiologie de Bourgogne and the Ligue Contre le Cancer. 


\section{Legends for Figures}

Figure 1: Sirius red staining showing collagen deposition in the (A) perivascular (B) subepicardial regions of the left ventricular myocardium in untreated (C) and treated (DOX) (bright field microscopy: left panels and polarization microscopy: right panels). Magnifications are $\times 20$

Figure 2: Quantification of collagen deposition in the (A) perivascular (B) epicardial regions. C: control group, DOX: treated group. ${ }^{*} \mathrm{P}<0.05$. (number of rats; $\mathrm{C}: \mathrm{n}=4 ; \mathrm{DOX}: \mathrm{n}=4$ )

Figure 3: mRNA levels of atrial natriuretic factor (ANF), myosin heavy chain $\beta$ ( $\beta$-MHC), vascular endothelial growth factor (VEGFa), sarcoplasmic reticulum $\mathrm{Ca}^{+2}$-ATPase (SERCA2a) and heme oxygenase-1 (HMOX) in untreated (C) and treated (DOX).

The values are means \pm SEM (number of rats; C: $n=8$; DOX: $n=8$ ).

Figure 4: Correlation between ANF, $\beta-\mathrm{MHC}$ and SERCA2a expressions and $+\mathrm{dP} / \mathrm{dTmax}$ $(\mathrm{mmHg} / \mathrm{s})$ in untreated $(\mathrm{C})$ and treated $(\mathrm{DOX})$ rats (number of rats; $\mathrm{C}: \mathrm{n}=8$; DOX: $\mathrm{n}=8)$. 
JPET \# 185892

Table 1: Primers used for comparative quantitative polymerase chain reaction analysis

\begin{tabular}{|l|l|l|l|l|}
\hline Symbols & Abbreviation & Genebank & Forward & Reverse \\
\hline ANF & Nppa & NM_012612 & CGTATACAGTGCGGTGTCCAAC & CCGAGAGCACCTTCTCTCTGAGA \\
\hline VEGFa & Vegfa & NM_031836 & TGGACCCTGGCTTTACTG & GGACGGCTTGAAGATATACTC \\
\hline HMOX1 & $\boldsymbol{H m o x 1}$ & NM_012580 & TGACAGAGGAACACAAAGACC & TGAGTGTGAGGACCCATCG \\
\hline $\boldsymbol{\beta}$-MHC & $\boldsymbol{M y h 7}$ & NM_017240 & TTGCTGTTATTGCTGCCATTG & CAAATCGGGAGGAGTTATCATTC \\
\hline SERCA2a & Atp2a & NM_017290 & TGTATCGACAGGACAGAAAGAGT & TGATGAGCGAGACAGATTCACCTG \\
\hline
\end{tabular}


Table 2: Body weight, heart weight and heart to body weight ratio in control group (C) and doxorubicin group (DOX), 2 months after the end of the treatment $\left({ }^{* * *} \mathrm{P}<0.001,{ }^{* *} \mathrm{P}<0.01\right.$ : DOX vs. C). The values are means \pm SEM of $n$ (number of rats; $C: n=8 ; D O X: n=8$ ).

\begin{tabular}{cccc}
\hline & Body weight & Heart weight & Heart to body \\
& $(\mathbf{g})$ & $(\mathrm{g})$ & weight $\left(\times \mathbf{1 0}^{-4}\right)$ \\
\hline $\mathbf{C}$ & $494 \pm 9$ & $1.00 \pm 0.02$ & $20.4 \pm 0.5$ \\
DOX & $378 \pm 13 * *$ & $0.87 \pm 0.04 * *$ & $23.0 \pm 0.3 * * *$ \\
\hline
\end{tabular}


Table 3: Cardiac functional parameters evaluated in vivo by left ventricle catheterization in the control group (C) and the doxorubicin group (DOX), 2 months after the end of the treatment $\left({ }^{* *} \mathrm{P}<0.01,{ }^{*} \mathrm{P}<0.05\right.$ : DOX $v s \mathrm{C}$ ). The values are means $\pm \mathrm{SEM}$ (number of rats; $\mathrm{C}$ : $n=8 ;$ DOX: $n=8)$.

\begin{tabular}{ccccc}
\hline HR & LVDP & $+\mathbf{+ d P / d T}$ & $\mathbf{- d P / d T}$ \\
& $($ beats/min) & $(\mathbf{m m H g})$ & $(\mathbf{m m H g} / \mathbf{s})$ & $(\mathbf{m m H g} / \mathbf{s})$ \\
\hline $\mathbf{C}$ & $343 \pm 7$ & $121 \pm 6$ & $3807 \pm 230$ & $3549 \pm 300$ \\
DOX & $325 \pm 12$ & $97 \pm 7 *$ & $2827 \pm 259 * *$ & $2628 \pm 308$ \\
\hline
\end{tabular}


Table 4: Plasma and cardiac oxidative stress parameters evaluated 2 months after the end of the treatment in the control group $(\mathrm{C})$ and the doxorubicin group $(\mathrm{DOX}){ }^{* * *} \mathrm{P}<0.001,{ }^{* *} \mathrm{P}<$ 0.01, ${ }^{*} \mathrm{P}<0.05$ : DOX vs. C). The values are means \pm SEM of $\mathrm{n}$ (number of rats; $\mathrm{C}: \mathrm{n}=8$; DOX: $n=8)$.

\begin{tabular}{|c|c|c|c|c|c|}
\hline & \multicolumn{3}{|c|}{ Plasma } & \multicolumn{2}{|c|}{ Myocardium } \\
\hline & $\begin{array}{c}\text { TBARS } \\
\text { (nmol/g prot.) }\end{array}$ & $\begin{array}{l}\text { Ascorbate } \\
(\mu \mathrm{mol} / \mathrm{L})\end{array}$ & $\begin{array}{c}\text { AFR/ascorbate } \\
(\mathrm{AU} / \mu \mathrm{mol} / \mathrm{L})\end{array}$ & $\begin{array}{c}\text { TBARS } \\
(\mu \mathrm{mol} / \mathrm{g} \text { tissue })\end{array}$ & $\begin{array}{c}\text { DHE }\left(10^{-4)}\right. \\
\text { (\%fluo./nucl.) }\end{array}$ \\
\hline $\mathrm{C}$ & $22 \pm 1$ & $42.4 \pm 3.5$ & $51 \pm 4$ & $13.9 \pm 1.4$ & $4.61 \pm 1.10$ \\
\hline DOX & $28 \pm 1 * *$ & $21.2 \pm 1.7 * * *$ & $76 \pm 6^{* *}$ & $21.7 \pm 3.3^{*}$ & $9.14 \pm 1.81 *$ \\
\hline
\end{tabular}

